ELECTRONIC LETTER

\title{
Mitochondrial DNA haplogroup distribution within Leber hereditary optic neuropathy pedigrees
}

\author{
P Y W Man, N Howell, D A Mackey, S Nørby, T Rosenberg, D M Turnbull, P F Chinnery
}

J Med Genet 2004;41:e41 (http://www.jmedgenet.com/cgi/content/full/41/4/e41). doi: 10.1136/jmg.2003.011247

L eber hereditary optic neuropathy (LHON; OMIM \#535000) is a mitochondrial genetic disease that - causes blindness in young adults, with an estimated minimum prevalence of 3.2 per 100000 in the north east of England. ${ }^{1}$ It classically presents as bilateral subacute loss of central vision due to the focal neurodegeneration of the retinal ganglion cell layer. Over $95 \%$ of cases are principally due to one of three "primary" mtDNA point mutations: $3460 \mathrm{G} \rightarrow \mathrm{A}, 11778 \mathrm{G} \rightarrow \mathrm{A}$, and $14484 \mathrm{~T} \rightarrow \mathrm{C}$, all of which involve genes that encode complex I subunits of the mitochondrial respiratory chain. However, less than $\sim 50 \%$ of male and $\sim 10 \%$ of female LHON carriers will develop the optic neuropathy. ${ }^{23}$ This marked incomplete penetrance and gender bias clearly indicates that additional genetic and/or environmental factors are required for the phenotypic expression of the pathogenic mtDNA mutations in LHON. However, these secondary factors remain poorly defined at the present time.

There has recently been considerable interest in the possible role of the mtDNA background on the phenotypic expression of mitochondrial genetic disorders. The hypothesis is that on their own, some polymorphisms are selectively "neutral" but that in specific combinations, they act in a synergistic, deleterious manner with established pathogenic mtDNA mutations to increase the risk of disease expression or to produce a more severe clinical outcome. ${ }^{4}$ The following nucleotide substitutions are found at a higher frequency in LHON patients relative to controls: $:^{5-7} \quad 4216 \mathrm{~T} \rightarrow \mathrm{C}, \quad 4917 \mathrm{~A} \rightarrow \mathrm{G}, \quad 9804 \mathrm{G} \rightarrow \mathrm{A}$, $9438 \mathrm{G} \rightarrow \mathrm{A}, \quad 13708 \mathrm{G} \rightarrow \mathrm{A}, \quad 15257 \mathrm{G} \rightarrow \mathrm{A}, \quad$ and $\quad 15812 \mathrm{G} \rightarrow \mathrm{A}$. Phylogenetic analysis has shown that $4216 \mathrm{~T} \rightarrow \mathrm{C}$, $13708 \mathrm{G} \rightarrow \mathrm{A}, 15257 \mathrm{G} \rightarrow \mathrm{A}$, and $15812 \mathrm{G} \rightarrow \mathrm{A}$ all cluster on a specific mtDNA background, haplogroup $\mathrm{J}$, which is one of the nine haplogroups that define populations of European ancestry. ${ }^{8}$ ' Several studies have subsequently found that LHON pedigrees that harbour the $11778 \mathrm{G} \rightarrow \mathrm{A}$ and $14484 \mathrm{~T} \rightarrow \mathrm{C}$ mutations are apparently not randomly distributed along the phylogenetic tree, but tend to show a preferential association with haplogroup J (table 1). It has therefore been argued that these polymorphic variants interact with the primary mtDNA mutations, increasing the risk of visual loss among LHON carriers. However, the potential pathogenic role of these so-called "secondary" mtDNA mutations in LHON is still controversial. All the association studies published so far involved a relatively small number of pedigrees collected over a wide geographical area by centres with a specialist interest in LHON, thereby raising the possibility of ascertainment bias. To investigate further the presumed association between primary LHON mutations and haplogroup J, we determined the haplogroup distribution of a rigorously defined, population based LHON cohort from the north east of England, and carried out a systematic statistical review of the literature.

\section{Key points}

- Over $95 \%$ of Leber hereditary optic neuropathy (LHON) pedigrees harbour one of three mitochondrial DNA (mtDNA) point mutations: $3460 \mathrm{G} \rightarrow \mathrm{A}$, $11778 \mathrm{G} \rightarrow \mathrm{A}$, or $14484 \mathrm{~T} \rightarrow \mathrm{C}$. However, additional genetic and/or environmental factors influence the penetrance of the primary mtDNA mutations that cause focal degeneration of the optic nerve in LHON.

- There is evidence that the mtDNA background could be relevant for the phenotypic expression of LHON.

- We carried out a meta-analysis of 297 published LHON pedigrees and confirmed the strength of the association between one specific mtDNA lineage, haplogroup J, and two of the primary LHON mutations: $11778 \mathrm{G} \rightarrow \mathrm{A}$ (odds ratio $(\mathrm{OR})=3.48,95 \%$ confidence interval (CI) 2.36 to 5.15) and $14484 \mathrm{~T} \rightarrow \mathrm{C}(\mathrm{OR}=27.53,95 \% \mathrm{Cl} 14.53$ to 52.13$)$, and confirmed the absence of an association with the $3460 \mathrm{G} \rightarrow \mathrm{A}$ mutation $(\mathrm{OR}=1.29,95 \% \mathrm{Cl} 0.57$ to 2.90).

- The most compelling explanation is that the risk of visual loss in LHON carriers with the $11778 \mathrm{G} \rightarrow \mathrm{A}$ and $14484 \mathrm{~T} \rightarrow \mathrm{C}$ mutations is increased by haplogroup J, and by extension, one or more of the m+DNA polymorphisms that define this haplogroup.

\section{MATERIALS AND METHODS \\ Study population}

Patients presenting with unexplained visual failure or suspected LHON within the north east of England were referred to the Northern Genetics Service based in Newcastle upon Tyne over the 12 year period from January 1990 to May 2002. Diagnostic mitochondrial genetic analysis was then carried out within the Mitochondrial Research Group of the Department of Neurology, University of Newcastle upon Tyne. This led to the identification of 15 genealogically distinct LHON pedigrees, confirmed by sequencing of the mtDNA D-loop region ${ }^{1}$ (table 2).

\section{Haplogroup determination}

One member of each pedigree was analysed and the haplogroup was determined by restriction enzyme analysis of the relevant PCR amplified mtDNA fragment, as described previously. ${ }^{10}$ The haplogroup distribution of 179 normal

Abbreviations: $L H O N$, Leber hereditary optic neuropathy; mHDNA, mitochondrial DNA 
controls from the north east of England had also been determined previously using the same protocol. ${ }^{11}$

\section{Systematic review}

Published studies that had analysed haplogroup distribution in LHON pedigrees were identified by searching the main electronic databases (MedLine and Web of Science) from 1988, when the first LHON mutation was reported. ${ }^{12}$ The keywords used in the search strategy were "optic atrophy", "mitochondrial DNA", "haplogroup", and "phylogeny". The reference lists of relevant papers were also assessed for the presence of additional studies not listed in these databases. Finally, the main investigators in the field of mitochondrial genetics were also contacted personally to obtain any unpublished data that might clarify some of their published results, especially if the raw data were not provided in the original paper.

\section{Study selection}

For the purpose of this review, studies (published or unpublished) were included only if sufficient data had been collected by the investigators to allow the haplogroup to be clearly deduced for their LHON pedigrees. In some of these studies, haplogroup status was not reported directly. However, pedigrees could still be grouped as being either J or non-J, as long as the polymorphic status at nucleotide positions 4216 and 13708 had been determined. ${ }^{9}{ }^{10}$ As far as possible, we tried to ascertain that all included pedigrees were unrelated and of European extraction.

\section{Statistical analysis}

A meta-analysis was carried out using the Mantel-Haenszel method as implemented in the Cochrane Review Manager ${ }^{\mathrm{TM}}$ software (version 4.1). A fixed effect model was adopted given the lack of significant heterogeneity between the included studies (http://www.cochrane.de/cochrane/hbook.htm).

\section{RESULTS}

In our population based LHON cohort from the north east of England, there was a trend towards haplogroup J being overrepresented in $11778 \mathrm{G} \rightarrow \mathrm{A}$ and $14484 \mathrm{~T} \rightarrow \mathrm{C}$ pedigrees compared with our control population, but this was not statistically significant because of the small number of pedigrees involved (table 2). A total of 10 other haplogroup $\mathrm{J}$ association studies were identified through our search strategy (table 1). The main findings of our statisical metaanalysis are summarised graphically by a forest plot (fig 1).

For the $3460 \mathrm{G} \rightarrow$ A pedigrees, the prevalence of haplogroup $\mathrm{J}(7.8 \%)$ was not significantly different to that in normal controls $(9.3 \%)$ (odds ratio $(\mathrm{OR})=1.29 \quad(95 \%$ CI 0.57 to
2.90)). Haplogroup J was moderately over-represented for the $11778 \mathrm{G} \rightarrow \mathrm{A}$ pedigrees $(26.8 \% \quad v$ only $9.3 \%$ in controls; $\mathrm{OR}=3.48 ; 95 \%$ CI 2.36 to 5.15$)$. There was a strong association between the $14484 \mathrm{~T} \rightarrow \mathrm{C}$ mutation and haplogroup J (OR $=27.53$; 95\% CI, 14.53 to 52.13$)$. Over $75 \%$ of the $14484 \mathrm{~T} \rightarrow \mathrm{C}$ LHON pedigrees belong to haplogroup $\mathrm{J}$, as against only $\sim 11 \%$ of the control mtDNAs.

\section{DISCUSSION}

This meta-analysis confirms the reported association between two of the primary LHON mutations, $11778 \mathrm{G} \rightarrow \mathrm{A}$ and $14484 \mathrm{~T} \rightarrow \mathrm{C}$, and haplogroup J. This was particularly marked for $14484 \mathrm{~T} \rightarrow \mathrm{C}$, with pedigrees harbouring this mutation being 30 times more likely to belong to this particular haplogroup than controls. While it is important to consider the possibility that these results are influenced by the method of ascertainment, particularly through a publication bias following the identification of the so-called "secondary" LHON mtDNA mutations in 1991, the magnitude of the association is so great that it seems unlikely that this can be the sole explanation. Moreover, our epidemiological study of LHON in a defined geographical region revealed the same trend towards a haplogroup $\mathrm{J}$ association, adding weight to our conclusion.

How can we explain the association between mtDNA haplogroup $\mathrm{J}$ and the $11778 \mathrm{G} \rightarrow \mathrm{A}$ and $14484 \mathrm{~T} \rightarrow \mathrm{C}$ mutations? It is conceivable that this could be due to an early founder effect, whereby the $11778 \mathrm{G} \rightarrow \mathrm{A}$ and $14484 \mathrm{~T} \rightarrow \mathrm{C}$ mutations arose early in the evolution of haplogroup $\mathrm{J}$, leading to its over-representation on that mitochondrial lineage. There is some evidence in support of this hypothesis in the Dutch population, ${ }^{13}$ but this cannot provide a complete explanation because all three primary LHON mutations have arisen multiple times on different mitochondrial backgrounds ${ }^{10}$ (see also the discussion in Howell et al ${ }^{13}$ and Brown et $\left.a l^{14}\right)$. Moreover, none of these mtDNA mutations has been found in the large sample of normal control mitochondrial genomes that belong to haplogroup J (for examples, see http:// www.genpat.uu.se/mtDB/index.html). There are a number of other possible explanations for this haplogroup $\mathrm{J}$ association. This particular mtDNA haplogroup $\mathrm{J}$ appears to be associated with successful ageing, ${ }^{15}$ a high complex I activity in spermatozoa, ${ }^{16}$ and a lower risk of developing Parkinson's disease, ${ }^{17}$ although the latter is still contentious. ${ }^{18}$ These putative "protective" effects of haplogroup J could confer a competitive advantage, leading to persistence of LHON mutations in the population, as has already been suggested, ${ }^{19}$ but it is difficult to see why this should be specific for the $11778 \mathrm{G} \rightarrow \mathrm{A}$ and $14484 \mathrm{~T} \rightarrow \mathrm{C}$ LHON mutations only. Although a point of great debate, the most compelling

Table 1 Summary of haplogroup association studies in LHON

\begin{tabular}{|c|c|c|c|c|c|c|c|c|c|c|c|c|c|}
\hline \multicolumn{2}{|l|}{ Study } & \multicolumn{3}{|c|}{ Controls } & \multicolumn{3}{|c|}{$3460 \mathrm{G} \rightarrow \mathrm{A}$} & \multicolumn{3}{|c|}{$11778 \mathrm{G} \rightarrow \mathrm{A}$} & \multicolumn{3}{|c|}{$14484 \mathrm{~T} \rightarrow \mathrm{C}$} \\
\hline Reference & Year & $\mathbf{n}$ & J & Non-J & $\mathbf{n}$ & J & Non-J & $\mathbf{n}$ & J & Non-J & $\mathbf{n}$ & J & Non-J \\
\hline 5 & 1991 & 175 & 16 & 159 & - & - & - & 36 & 4 & 32 & - & - & - \\
\hline 6 & 1991 & 175 & 16 & 159 & 9 & 2 & 7 & - & - & - & - & - & - \\
\hline 26 & 1992 & 179 & 25 & 174 & 3 & 0 & 3 & 14 & 7 & 7 & 5 & 3 & 2 \\
\hline 27 & 1993 & 175 & 16 & 159 & - & - & - & - & - & - & 15 & 12 & 3 \\
\hline 22 & 1994 & 160 & 16 & 144 & 8 & 0 & 8 & 16 & 2 & 14 & 9 & 8 & 1 \\
\hline 8 & 1995 & 175 & 16 & 159 & 10 & 1 & 9 & 17 & 4 & 13 & 8 & 6 & 2 \\
\hline 28 & 1997 & 67 & 5 & 62 & 4 & 1 & 3 & 23 & 10 & 13 & 21 & 14 & 7 \\
\hline 10 & 1997 & 99 & 7 & 92 & 7 & 0 & 7 & 28 & 11 & 17 & 2 & 2 & 0 \\
\hline 29 & 1997 & 529 & 33 & 496 & 3 & 0 & 3 & 13 & 4 & 9 & - & - & - \\
\hline 30 & 1999 & 78 & 9 & 69 & 2 & 0 & 2 & 27 & 4 & 23 & 2 & 1 & 1 \\
\hline Current stu & & 179 & 25 & 174 & 5 & 0 & 5 & 9 & 3 & 6 & 1 & 1 & 0 \\
\hline
\end{tabular}

In most of these studies, haplogroup distribution for a representative sample of normal controls from the local population was also reported. If the latter was no provided, this was sought either directly from the original investigators or from other published sources: Finland ${ }^{25}$ and the Netherlands (Dr G Barbujani, personal communication). 
Table 2 Haplogroup distribution in the north east of England

\begin{tabular}{lrllllll}
\hline \multicolumn{7}{c}{ Haplogroup } \\
\cline { 3 - 8 } Group & $\mathbf{n}$ & H & U & J & K & T & Others \\
\hline $3460 G \rightarrow A$ & 5 & 3 & 1 & - & 1 & - & - \\
$11778 G \rightarrow A$ & 9 & 3 & 1 & 3 & 2 & - & - \\
$14484 T \rightarrow C$ & 1 & - & - & 1 & - & - & - \\
Controls & 179 & $74(41)$ & $32(18)$ & $25(14)$ & $21(12)$ & $18(10)$ & $9(5)$ \\
\hline \% in brackets. & & & & & & &
\end{tabular}

explanation is that the risk of visual loss is increased by haplogroup J.

If this mtDNA background does have a deleterious effect, it would be expected that haplogroup $\mathrm{J}$ should result in a more pronounced respiratory chain defect, and thus influence the phenotype of LHON. Cybrid cell lines carrying the $11778 \mathrm{G} \rightarrow \mathrm{A}$ mutation and haplogroup $\mathrm{J}$ were shown to have a lower oxygen consumption and a longer doubling time compared with cell lines with the $11778 \mathrm{G} \rightarrow \mathrm{A}$ mutation alone. ${ }^{20}$ However, a recently published study showed no difference in respiratory chain function between cybrid cell lines harbouring mtDNA from different haplogroups on the same

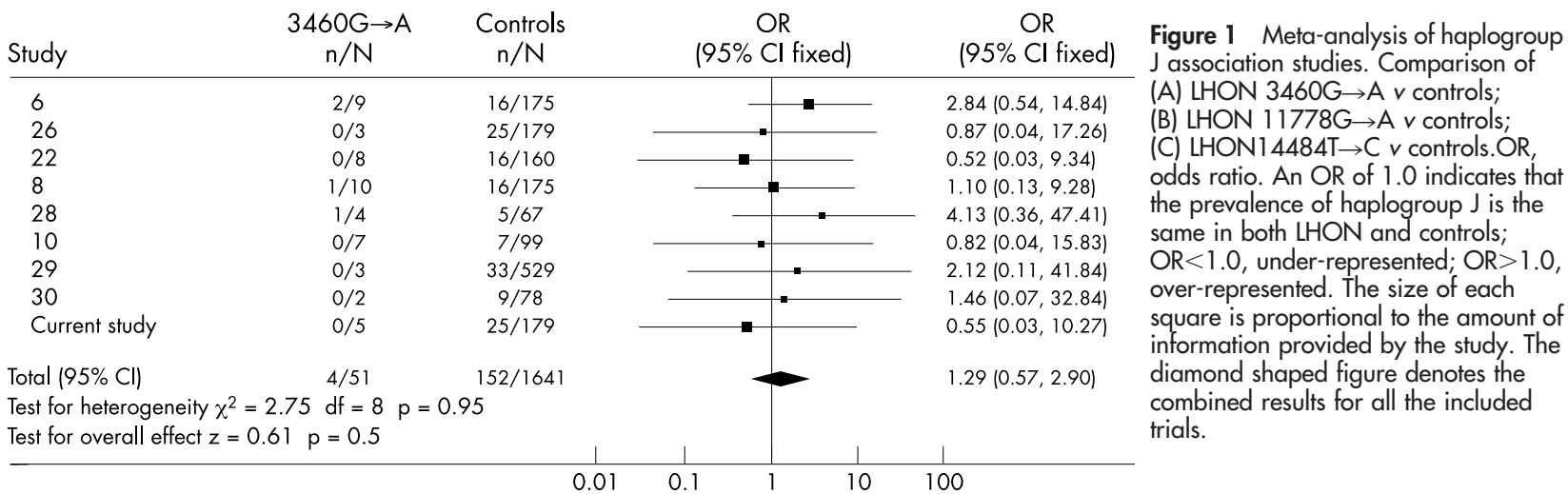

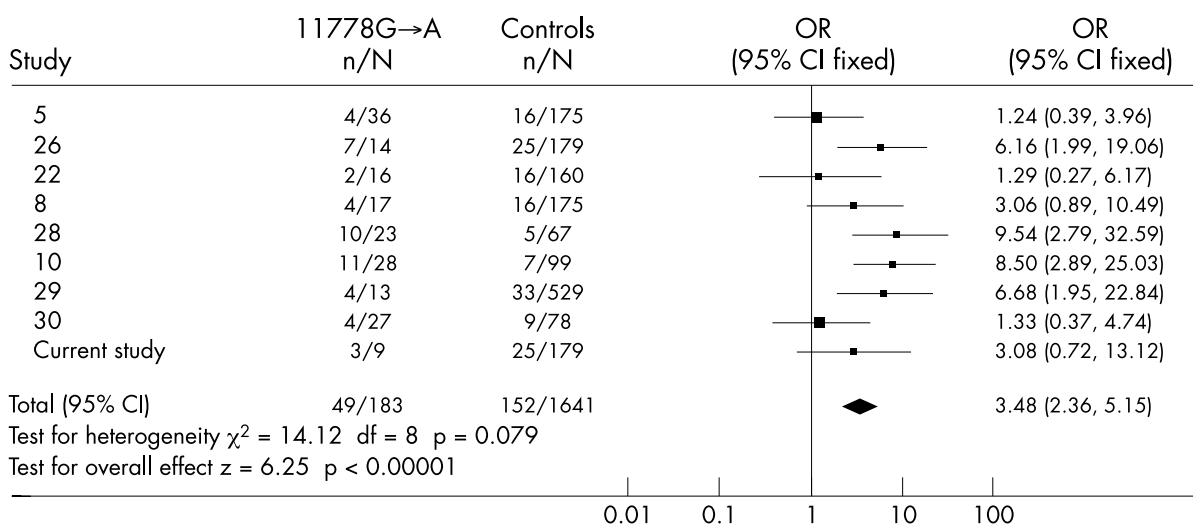

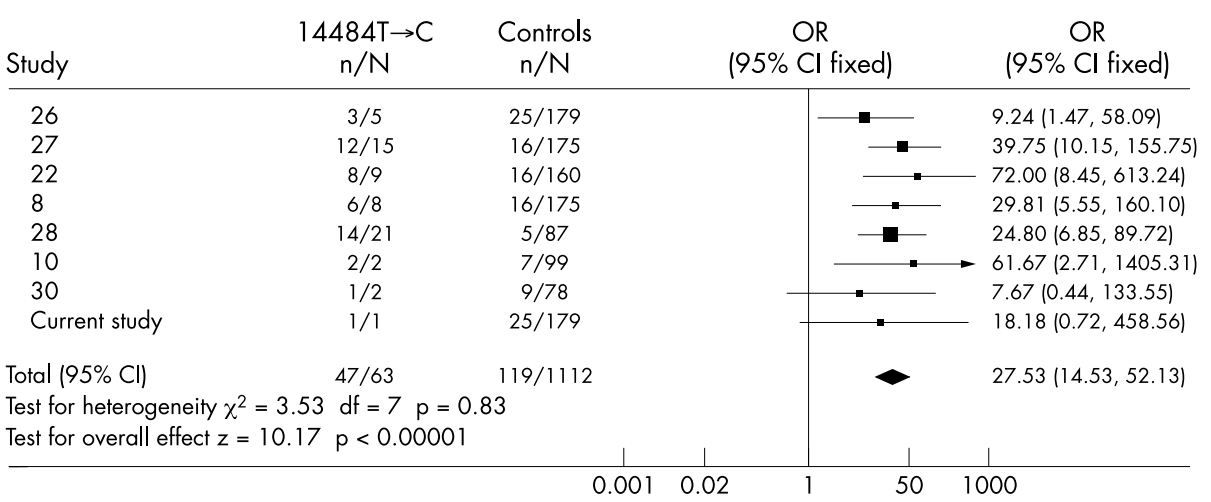


nuclear genetic background. ${ }^{19}$ In vivo magnetic resonance spectroscopy in patients harbouring the $11778 \mathrm{G} \rightarrow$ A mutation also failed to detect any deleterious effect in brain and skeletal muscle from haplogroup $\mathrm{J}^{21}$ The influence of haplogroup $\mathrm{J}$ on the biochemical features of the $14484 \mathrm{~T} \rightarrow \mathrm{C}$ mutation has not yet been determined. This result would be interesting in order to clarify the much stronger association of haplogroup J with $14484 \mathrm{~T} \rightarrow \mathrm{C}$ compared with $11778 \mathrm{G} \rightarrow \mathrm{A}$. However, these studies will require cautious interpretations, given that both in vitro and in vivo biochemical studies have produced conflicting results regarding the extent of respiratory chain dysfunction in LHON. There is currently no evidence that haplogroup $\mathrm{J}$ influences age of onset or final visual outcome in LHON, although this trend requires further confirmation in a larger LHON cohort. ${ }^{22}$ Haplogroup $\mathrm{J}$ is one of nine European specific haplogroups, and therefore it would also be expected that LHON should be more common in populations of European extraction. This hypothesis will be difficult to test, given the paucity of data regarding the prevalence of LHON in different ethnic groups, and potential confounding factors such as a population bottleneck. $^{23}$

The analysis presented here also provides strong statistically based evidence that there is no association between haplogroup $\mathrm{J}$ and the $3460 \mathrm{G} \rightarrow \mathrm{A}$ mtDNA mutation. This is a most intriguing finding, given the strong haplogroup affiliation for the two other primary LHON mutations. However, the $3460 \mathrm{G} \rightarrow \mathrm{A}$ mutation seems to behave differently in a number of ways. Firstly, $3460 \mathrm{G} \rightarrow \mathrm{A}$ is the LHON mutation most consistently associated with a significant biochemical complex I defect; secondly, compared with the $14484 \mathrm{~T} \rightarrow \mathrm{C}$ mutation, it is associated with a poorer visual outcome; and thirdly, it is associated with a less prominent gender bias. ${ }^{24}$ This evidence suggests that $3460 \mathrm{G} \rightarrow \mathrm{A}$ is perhaps a "stronger" mutation-that is, less susceptible to the epistatic and epigenetic factors influencing the expression of the $14484 \mathrm{~T} \rightarrow \mathrm{C}$ mutation and possibly the $11778 \mathrm{G} \rightarrow \mathrm{A}$ mutation.

Based on our meta-analysis of all published and unpublished datasets, there seems to be little doubt that the $14484 \mathrm{~T} \rightarrow \mathrm{C}$ mutation, and to a lesser extent the $11778 \mathrm{G} \rightarrow \mathrm{A}$ mutation, are over-represented in haplogroup J, but several additional questions remain unanswered. What is the combination of polymorphisms within haplogroup $\mathrm{J}$ that increases the risk of disease expression? Unfortunately, there are insufficient published data available to carry out haplogroup $\mathrm{J}$ sub-cluster analysis and explore further the differences reported in sub-clusters $\mathrm{Jl}$ and $\mathrm{J} 2 .{ }^{10}$ Why should the $3460 \mathrm{G} \rightarrow \mathrm{A}$ mutation prove refractory to the mitochondrial genetic background? We have as yet no answer. Addressing these important issues will not only advance our understanding of LHON, but will also have broader relevance for other pathogenic mtDNA mutations.

\section{ACKNOWLEDGEMENTS}

This work was supported by the Wellcome Trust (P F Chinnery, D M Turnbull), the Medical Research Council (D M Turnbull), the Eierman Foundation (N Howell), and the PPP Healthcare Trust ( $\mathrm{P}$ Y W Man). We wish to thank all the patients and their family members for their participation in this study, and the clinicians in the north of England who referred their patients for investigation. We are also grateful to S A Lynch, S McDonnell and G Ahearne for their work with LHON families. We are also indebted to the various investigators who kindly provided us with their unpublished haplogroup data.

\section{Authors' affiliations}

P Y W Man, D M Turnbull, P F Chinnery, Department of Neurology, The Medical School, University of Newcastle Upon Tyne, UK

N Howell, Mitokor, San Diego, CA, USA
D A Mackey, CERA, Royal Victorian Eye and Ear Hospital, Melbourne, Australia

S Nørby, Institute of Forensic Medicine, University of Copenhagen, Denmark

T Rosenberg, Gordon Norrie Centre for Genetic Eye Diseases, National Eye Clinic for the Visually Impaired, Hellerup, Denmark

Correspondence to: Dr P F Chinnery, Department of Neurology, The Medical School, University of Newcastle Upon Tyne, UK;

p.f.chinnery@ncl.ac.uk

Received 10 July 2003

Accepted 11 July 2003

\section{REFERENCES}

1 Man PY, Griffiths PG, Brown DT, Howell N, Turnbull DM, Chinnery PF. The epidemiology of Leber hereditary optic neuropathy in the north east of England. Am J Hum Genet 2003;72:333-9.

2 Seedorff T. The inheritance of Leber's disease: a geneological follow-up study. Acta Ophthalmol 1985;63:135-45.

3 Riordan-Eva P, Harding AE. Leber's hereditary optic neuropathy: the clinical relevance of different mitochondrial DNA mutations. J Med Genet 1995; 32:81-7.

4 Chinnery PF, Howell N, Andrews RM, Turnbull DM. Mitochondrial DNA analysis: polymorphisms and pathogenicity. J Med Genet 1999;36:505-10.

5 Johns DR, Berman J. Alternative simulataneous complex I mitochondrial DNA mutations in Leber's hereditary optic neuropathy. Biochem Biophys Res Commun 1991; 174:1324-30.

6 Johns DR, Neufeld MJ. Cytochrome b mutations in Leber hereditary optic neuropathy. Biochem Biophys Res Commun 1991;181:1358-64.

7 Johns DR, Neufeld MJ. Cytochrome c oxidase mutations in Leber hereditary optic neuropathy. Biochem Biophys Res Commun 1993;196:810-15.

8 Brown MD, Torroni A, Reckord CL, Wallace DC. Phylogenetic analysis of Leber's hereditary optic neuropathy mitochondrial DNAs indicates multiple independent occurrences of the common mutations. Hum Mutat 1995;6:311-25.

9 Torroni A, Huoponen K, Francalacci P, Petrozzi M, Morelli L, Scozzari R, Obinu D, Savontaus ML, Wallace DC. Classification of European mtDNAs from an analysis of three European populations. Genetics 1996; 144:1835-50.

10 Torroni A, Petrozzi M, D'Urbano L, Sellitto D, Zeviani M, Carrara F, Carducci C, Leuzzi V, Carelli V, Barboni P, De Negri A, Scozzari R. Haplotype and phylogenetic analyses suggest that one European-specific m+DNA background plays a role in the expression of Leber hereditary optic neuropathy by increasing the penetrance of the primary mutations 11778 and 14484. Am J Hum Genet 1997;60:1107-21.

11 Chinnery PF, Taylor GA, Howell N, Andrews RM, Morris CM, Taylor RW, McKeith IG, Perry RH, Edwardson JA, Turnbull DM. Mitochondrial DNA haplogroups and susceptibility to $A D$ and dementia with Lewy bodies. Neurology 2000;55:302-4.

12 Wallace DC, Singh G, Lott MT, Hodge JA, Schurr TG, Lezza AM, Elsas $\sqcup$ 2nd, Nikoskelainen EK. Mitochondrial DNA mutation associated with Leber's hereditary optic neuropathy. Science 1988;242:1427-30.

13 Howell N, Oostra RJ, Bolhuis PA, Spruijt L, Clarke LA, Mackey DA, Preston G Herrnstadt $C$. Sequence analysis of the mitochondrial genomes from dutch pedigrees with Leber hereditary optic neuropathy. Am J Hum Genet 2003;72:1460-9

14 Brown MD, Starikovskaya E, Derbeneva O, Hosseini S, Allen JC, Mikhailovskaya IE, Sukernik RI, Wallace DC. The role of mtDNA background in disease expression: a new primary LHON mutation associated with Western Eurasian haplogroup J. Hum Genet 2002;1 10:130-8.

15 De Benedictis G, Rose G, Carrieri G, De Luca M, Falcone E, Passarino G, Bonafe M, Monti D, Baggio G, Bertolini S, Mari D, Mattace R, Franceschi C. Mitochondrial DNA inherited variants are associated with successful aging and longevity in humans. FASEB J 1999;13:1532-6.

16 Ruiz-Pesini E, Lapena AC, Diez-Sanchez C, Perez-Martos A, Montoya J, Alvarez E, Diaz M, Urries A, Montoro L, Lopez-Perez MJ, Enriquez JA. Human mtDNA haplogroups associated with a high or reduced spermatozoa motility. Am J Hum Genet 2000;67:682-96.

17 van der Walt JM, Nicodemus KK, Martin ER, Scott WK, Nance MA, Watts RL, Hubble JP, Haines JL, Koller WC, Lyons K, Pahwa R, Stern MB, Colcher A, Hiner BC, Jankovic J, Ondo WG, Allen FH Jr, Goetz CG, Small GW, Mastaglia F, Stajich JM, McLaurin AC, Middleton LT, Scott BL, Schmechel DE, Pericak-Vance MA, Vance JM. Mitochondrial polymorphisms significantly reduce the risk of Parkinson disease. Am J Hum Genet 2003;72:804-11.

18 Ross OA, McCormack R, Maxwell LD, Duguid RA, Quinn DJ, Barnett YA, Rea IM, El-Agnaf OM, Gibson JM, Wallace A, Middleton D, Curran MD. m+4216C variant in linkage with the m+DNA TJ cluster may confer a susceptibility to mitochondrial dysfunction resulting in an increased risk of Parkinson's disease in the Irish. Exp Gerontol 2003:38:397-405.

19 Carelli V, Vergani L, Bernazzi B, Zampieron C, Bucchi L, Valentino M Rengo C, Torroni A, Martinuzzi A. Respiratory function in cybrid cell lines carrying European mtDNA haplogroups: implications for Leber's hereditary optic neuropathy. Biochim Biophys Acta 2002;1588:7-14

20 Vergani L, Martinuzzi A, Carelli V, Cortelli P, Montagna P, Schievano G Carrozzo R, Angelini C, Lugaresi E. MtDNA mutations associated with Leber's 
hereditary optic neuropathy: studies on cytoplasmic hybrid (cybrid) cells. Biochem Biophys Res Commun 1995;210:880-8.

21 Lodi R, Montagna P, Cortelli P, lotti S, Cevoli S, Carelli V, Barbiroli B. 'Secondary' 4216/ND1 and 13708/ND5 Leber's hereditary optic neuropathy mitochondrial DNA mutations do not further impair in vivo mitochondrial oxidative metabolism when associated with the 11778/ND4 mitochondrial DNA mutation. Brain 2000;123:1896-902.

22 Oostra RJ, Bolhuis PA, Zorn-Ende I, de Kok-Nazaruk MM, BleekerWagemakers EM. Leber's hereditary optic neuropathy: no significan evidence for primary or secondary pathogenicity of the 15257 mutation. Hum Genet 1994:94:265-70

23 Macmillan C, Johns TA, Fu K, Shoubridge EA. Predominance of the T14484C mutation in French-Canadian families with Leber hereditary optic neuropathy is due to a founder effect. Am J Hum Genet 2000;66:332-5.

24 Man PY, Turnbull DM, Chinnery PF. Leber hereditary optic neuropathy. J Med Genet 2002;39:162-9.

25 Finnila S, Majamaa K. Phylogenetic analysis of mtDNA haplogroup TJ in a Finnish population. J Hum Genet 2001;46:64-9.
26 Mackey DA, Buttery RG. Leber hereditary optic neuropathy in Australia. Austr New Zealand J Med 1992;20:177-84.

27 Johns DR, Heher KL, Miller NR, Smith KH. Leber's hereditary optic neuropathy. Clinical manifestations of the 14484 mutation. Arch Ophthalmol 1993;111:495-8.

28 Hofmann S, Jaksch M, Bezold R, Mertens S, Aholt S, Paprotta A, Gerbitz KD. Population genetics and disease susceptibility: characterization of central European haplogroups by m+DNA gene mutations, correlation with D loop variants and association with disease. Hum Mol Genet 1997:6: 1835-46.

29 Lamminen T, Huoponen K, Sistonen P, Juvonen V, Lahermo P, Aula P, Nikoskelainen E, Savontaus ML. M+DNA haplotype analysis in Finnish families with Leber hereditary optic neuroretinopathy. Eur J Hum Genet 1997:5:271-9.

30 Norby S, Saillard J, Magalhaes P, Schwartz M, Rosenberg T. The spectrum of pathogenic mutations and mtDNA haplogroups among Danish lineages manifesting Leber hereditary optic neuropathy. Am J Hum Genet 1999;65:2219. 


\section{Correction}

Man PYW, Howell N, Mackey DA, et al. Mitochondrial DNA haplogroup distribution within Leber hereditary optic neuropathy pedigrees. J Med Genet 2004;41:e41 doi:10.1136/ jmg.2003.011247.

Man PYW, Morris CM, Zeviani M, et al. The role of APOE in the phenotypic expresion of Leber hereditary optic neuropathy. J Med Genet 2003;40:e41 doi:10.1136/jmg.40.4.e41.

Man PYW, Turnbull DM, Chinnery PF. Leber hereditary optic neuropathy. J Med Genet 2002;39:162-169 doi:10.1136/jmg.39.3.162.

The first author's name of all three papers has been corrected to Patrick Yu-Wai-Man.

J Med Genet 2016:53:493.

doi:10.1136/jmg-2003-011247corr1, doi:10.1136/jmg-40.4.e41corr1, and doi:10.1135.jmg.39.3.162corr1

CrossMark 